\title{
Development and experimental evaluation of a complete solar thermophotovoltaic system
}

\author{
Alejandro Datas and Carlos Algora
}

\begin{abstract}
We present a practical implementation of a solar thermophotovoltaic (TPV) system. The system presented in this paper comprises a sunlight concentrator system, a cylindrical cup-shaped absorber/emitter (made of tungsten coated with $\mathrm{HfO}_{2}$ ), and an hexagonal-shaped water-cooled TPV generator comprising 24 germanium TPV cells, which is surrounding the cylindrical absorber/emitter. This paper focuses on the development of shingled TPV cell arrays, the characterization of the sunlight concentrator system, the estimation of the temperature achieved by the cylindrical emitters operated under concentrated sunlight, and the evaluation of the full system performance under real outdoor irradiance conditions. From the system characterization, we have measured short-circuit current densities up to $0.95 \mathrm{~A} / \mathrm{cm}^{2}$, electric power densities of $67 \mathrm{~mW} / \mathrm{cm}^{2}$, and a global conversion efficiency of about $0.8 \%$. To our knowledge, this is the first overall solar-to-electricity efficiency reported for a complete solar thermophotovoltaic system. The very low efficiency is mainly due to the overheating of the cells (up to $120^{\circ} \mathrm{C}$ ) and to the high optical concentrator losses, which prevent the achievement of the optimum emitter temperature. The loss analysis shows that by improving both aspects, efficiencies above $5 \%$ could be achievable in the very short term and efficiencies above $10 \%$ could be achieved with further improvements. Copyright (C) 2012 John Wiley \& Sons, Ltd.
\end{abstract}

KEYWORDS

solar thermophotovoltaic; TPV cell array; sunlight concentration; high-temperature emitters

\section{INTRODUCTION}

Solar thermophotovoltaic (STPV) systems were proposed for the first time by Swanson in 1979 [1]. In these systems, an intermediate material is heated by the sun, re-radiating the absorbed energy towards a photovoltaic (PV) device (TPV cell). Then, using spectral control elements between the cells and the emitter (the surface of the intermediate material facing the TPV cells) or using reflectors at the back side of the TPV cells, the net radiation transfer from the emitter to the cells is restricted to photons with energies above the bandgap of the TPV cells, and the sub-bandgap photons are turned back to the emitter. This concept has one of the highest solar-to-electricity ultimate conversion efficiency limit among the other photovoltaic approaches $(85 \%$ [2]). Besides, the presence of an intermediate hightemperature material allows the combination of this technology with thermal storage systems and an alternate fuel/gas input $[3,4]$. Therefore, the main attractiveness of the STPV technology is that it could allow building a highly efficient, stable (non-intermittent), modular, and scalable solution to generate electricity from the sun energy. Besides, this technology is benefited from the fact that it requires a minimum number of moving parts (just needed in the sun-tracking system) compared with other solar-thermal technologies, as they are the Dish-Stirling systems.

In our previous works concerning the theoretical analysis of STPV systems, we demonstrated that efficiencies and electrical power densities of about $10 \%$ and $3 \mathrm{~W} / \mathrm{cm}^{2}$ could be achieved in the short term, using presently available devices [5]. Besides, efficiencies and electrical power densities above $30 \%$ and $50 \mathrm{~W} / \mathrm{cm}^{2}$, respectively, are plausible in the long term [6].

Many other theoretical analyses of STPV systems can be found in the literature $[1,7-14,2,3,15,16]$. However, just a few references to practical implementation of STPV systems are found. In this regard, highlighted are the work 
carried out in the mid-1990s by the US aerospace manufacturer McDonnell Douglas (later merged with Boeing in 1997) $[17,18,4,19-27]$ and by EDTEK Inc. during the early 2000s [28]. However, in these references, an experimental solar-to-electricity efficiency is not reported for the full system, either because most of the tests were performed on test bed units but not on complete STPV systems (in the case of the McDonnell Douglas system) or because of the failure of different components that prevented operating the system under full sun-power conditions (EDTEK system).

More recently, STPV systems has been developed in the frame of the European Commission funded project FULLSPECTRUM [29], which ended in 2008. In this project, a STPV system designed by the Ioffe PhysicoTechnical Institute (St. Petersburg, Russia) was independently implemented at both Ioffe Institute and at Instituto de Energıa Solar Universidad Politécnica de Madrid (IES-UPM; Madrid, Spain). In this paper, we present the implementation and characterization of a full STPV system developed at IES-UPM (an early prototype description can be found in [30]). References to the Ioffe's system can be found in [31-39].

\section{GENERAL DESCRIPTION OF THE STPV SYSTEM}

Figure 1 shows a draft of the different pieces comprising the full cylindrical STPV system (excluding the sunlight concentrator system). In this system, the concentrated sunlight heats a cup-shaped cylindrical absorber/emitter. The cylindrical enclosure plays the role of sunlight absorber, whereas the outer walls play the role of an emitter. This configuration provides a high emitter-toabsorber area ratio, required in STPV systems to enhance the energy transfer to the cells rather than the energy emitted back from the absorber to the sun. Besides, the cylindrical enclosure provides a very high absorbance of the incident sun energy independently of the absorptivity of the material making up the inner walls of that enclosure. Tungsten is an excellent candidate to manufacture this component because of its low emissivity at long wavelengths, its high melting point $\left(3400^{\circ} \mathrm{C}\right)$, and its low vapor pressure. Besides, the spectral emissivity of tungsten for short wavelengths can be enhanced engineering the tungsten surface, for instance, depositing anti-reflective coatings.

The absorber/emitter component is hosted within a quartz chamber in which an argon flow is established to prevent the emitter oxidation. Argon was selected because it is an inert gas and because it has a very low heat capacity, important to minimize the convective heat losses at the emitter. Besides, the quartz chamber is sealed and over-pressurized to avoid air flow inside the chamber.

A hexagonal water-cooled heat-sink made of brass was manufactured to hold six TPV cell modules, containing

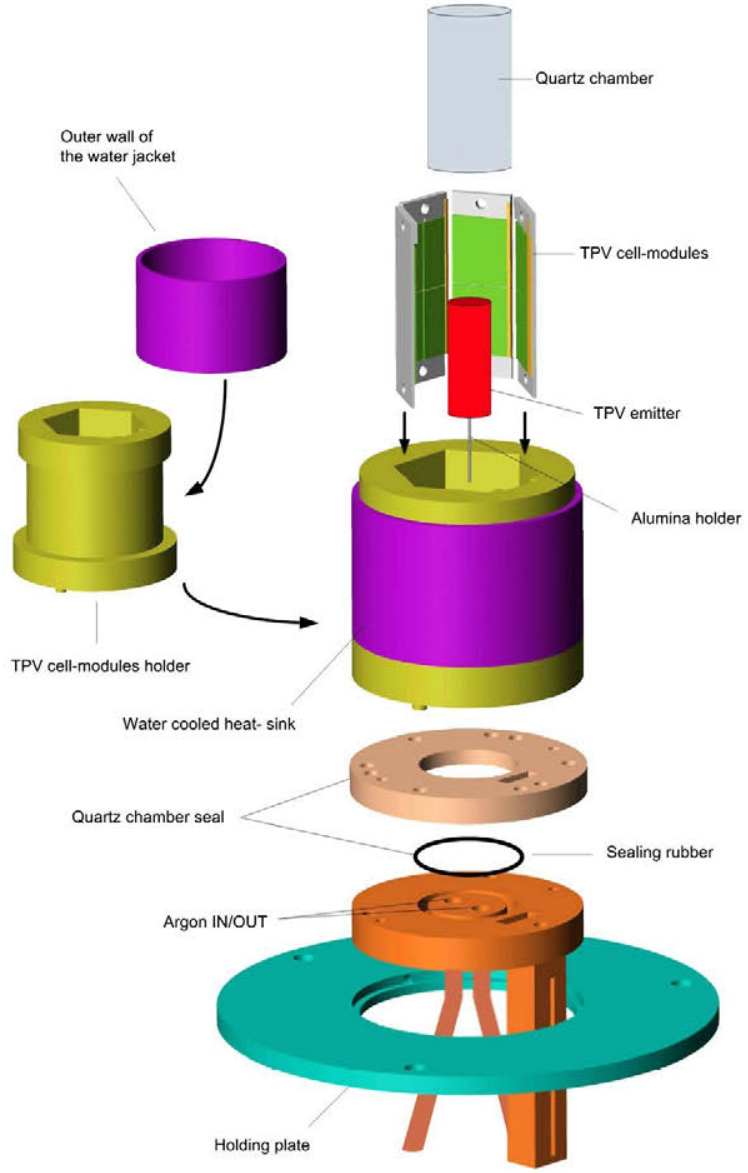

Figure 1. Integration of the pieces comprising the STPV system prototype.

four germanium TPV cells each. A germanium semiconductor was used because of its relatively low bandgap energy $(0.661 \mathrm{eV})$, which is convenient for converting the light coming from bodies at the typical temperature range of $1000-2000^{\circ} \mathrm{C}$. Although other low bandgap semiconductors (like $\mathrm{GaSb}$, InGaAs, or InGaAsSb) could provide higher efficiencies, germanium has been elected because of two reasons: first, because it is one of the cheapest alternatives for manufacturing low bandgap TPV cells [40] and second, because of the recent worldwide interest on this kind of cells, which are also used as bottom cell in multi-junction solar cells.

Within the TPV module, two pairs of cells are series connected using the shingling arrangement in order to minimize the shadowing factor of the array. Then, these pairs are interconnected in parallel to minimize the impact of the non-uniform illumination along the axial direction of the module. Finally, the modules are fixed to the watercooled heat-sink, using a thermal grease, to enhance the heat dissipation.

The final TPV generator comprises 24 cells (divided into six modules), representing a total active area for the cells of $37.2 \mathrm{~cm}^{2}$. It represents an effective concentration 


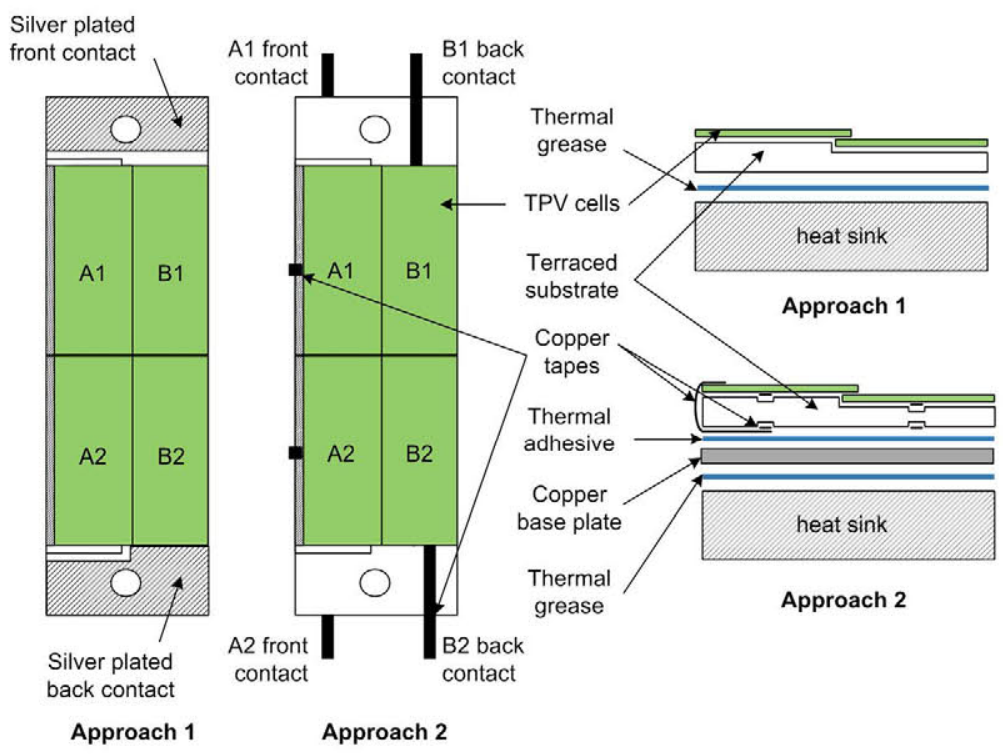

Figure 2. Comparison between approaches 1 and 2 for assembling the shingled TPV modules.

factor $^{1}$ of $97 \times$ (in terms of the reduction of required semiconductor area with respect to flat-panel PV systems).

Within the FULLSPECTRUM project, tungsten emitters were manufactured by the Ioffe Institute, and they were coated with $\mathrm{HfO}_{2}$ anti-reflective coatings at Fraunhofer-ISE (Freiburg, Germany). The Ge TPV cells were developed at Fraunhofer-ISE $[41,42]$. In what follows, we describe the development and characterization of a complete STPV system that integrates these components.

\section{TPV CELL MODULES}

The TPV cell module comprises four germanium TPV cells. Each cell has a total active area of $1.55 \mathrm{~cm}^{2}$ and a wide lateral bus-bar. Taking advantage of the lateral bus-bar, the shingling arrangement $[43,44]$ is used to interconnect the cells in the radial direction within each module (Figure 2). This provides a high packing density and allows the series connection between the cells, required to enhance the output voltage of the array. Parallel connection is used in the axial direction to avoid current mismatch losses occasioned by the non-uniform illumination of the module in that direction.

\subsection{TPV cell module substrate}

The adoption of the shingled approach requires the use of a terraced substrate to provide mechanical support (Figure 2). Besides, the substrate must provide electrical

'The TPV active cells area $\left(37.2 \mathrm{~cm}^{2}\right)$ to the Fresnel lens area $\left(3600 \mathrm{~cm}^{2}\right)$ ratio isolation between the cells, a high thermal conductivity, and a coefficient of thermal expansion (CTE) similar to the one of the semiconductors (about 6-7 ppm/K). In this regard, we have manufactured two kinds of terraced substrates:

- Metallic substrate: We have used copper, which is a very easily machinable and highly thermally conductive material $(400 \mathrm{~W} / \mathrm{m} \mathrm{K})$. However, it has a very high CTE value (17 ppm/K). Besides, it must be electrically isolated to allow the series connection between the cells. The electrical isolation has been carried out covering the $\mathrm{Cu}$ substrate with the Corr-Paint CP3000 water-based ceramic. This ceramic can be dispensed using a pneumatic spray gun, which allows obtaining a relatively good surface uniformity and also reproducing very well the relief of the mechanized metallic substrate.

- Ceramic substrate: We have used Boron Nitride

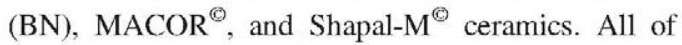
them provide electrical isolation and can be easily machined to perform the terraced substrates. Among them, Shapal-M is the best alternative because it shows the highest thermal conductivity $(100 \mathrm{~W} / \mathrm{m} \mathrm{K})$ and the closer CTE to the one of the semiconductors $(5.2 \mathrm{ppm} / \mathrm{K})$. However, both BN $(15-50 \mathrm{~W} / \mathrm{m} \mathrm{K}$ and $1.1 \mathrm{ppm} / \mathrm{K})$ and MACOR $(1.5 \mathrm{~W} / \mathrm{m} \mathrm{K}$ and $13 \mathrm{ppm} / \mathrm{K})$ are much cheaper than Shapal-M and are easier to mechanize.

\subsection{TPV cells assembling}

We have used two different approaches to interconnect the four Ge cells within the module (Figure 2): 
- Approach 1: The cells are connected by means of two soldering steps. In a first step, the solder alloy $96.5 \mathrm{Sn}$ $3.5 \mathrm{Ag}\left(221^{\circ} \mathrm{C}\right.$ melting point) is dispensed on the bus-bar of the bottom cell, and a protective polymeric paint is applied to the perimeter of the bottom cell to prevent the solder from flowing and shortcutting the cell. Then, the top cell is placed over the bottom cell using a terraced ceramic (not wettable by the solder) substrate for mechanical support, and the full structure is slowly heated up to $270^{\circ} \mathrm{C}$ $\left(50^{\circ} \mathrm{C}\right.$ above the melting point of the solder). The result of this process is a fragile shingled pair of two cells (this specific step was suggested by Dr. Loeckenhoff, personal communication) (FraunhoferISE, Freiburg, Germany). In a second step, the back sides of the cells are soldered to the metallic traces previously deposited on the terraced substrate. For that, $58 \mathrm{Bi} 42 \mathrm{Sn}$ solder $\left(138^{\circ} \mathrm{C}\right.$ melting point $)$ is used because of its lower melting point, to allow a lowertemperature soldering process to avoid the melting of the shingling junction between the two cells. Finally, in order to connect the front side of the top cells to the external module contacts, we have used the parallel gap welding (PGW) at Interuniversity Microelectronics Centre facilities (Leuven, Belgium). Figure 3 shows pictures of the full TPV generator comprising six TPV modules manufactured according to this approach.

- Approach 2: In contrast to the previous approach, in this case the cells are connected by means of just one soldering process. This process not only includes the shingling connection of the cells but also the soldering of tinned-copper tapes $(35 \mu \mathrm{m}$ thick, $1 \mathrm{~mm}$ width $)^{2}$ to the bus-bar of the top cells and the back side of the bottom cells. The shingled pairs resulting from this process are then bonded to the terraced substrate using either a thermally conductive epoxy (LOCTITE 315) or thermal conductive adhesive tapes (Bond-Ply 100). Note that in this approach, the terraced substrates must present additional grooves

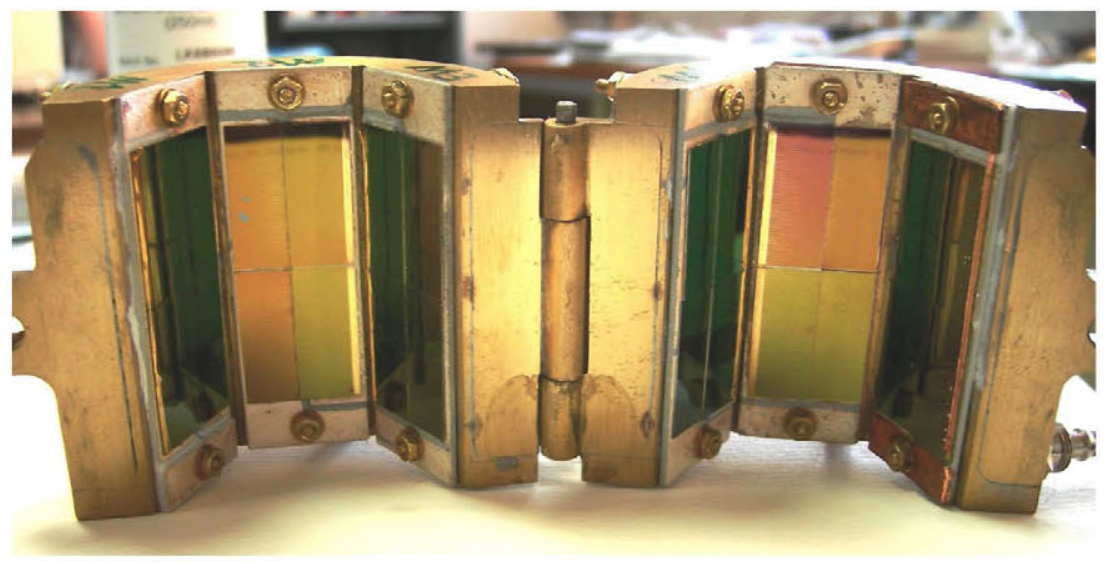

(a)

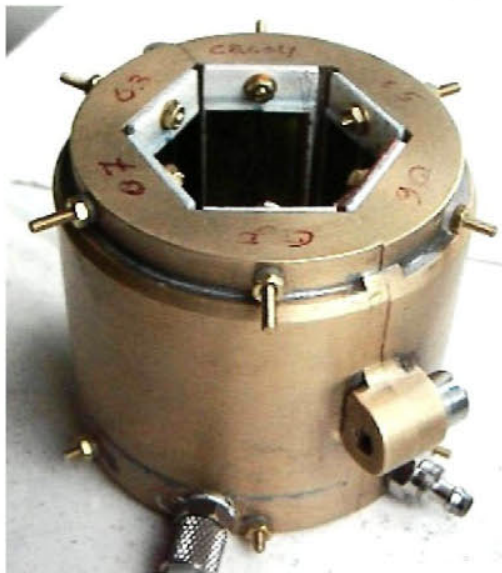

(b)

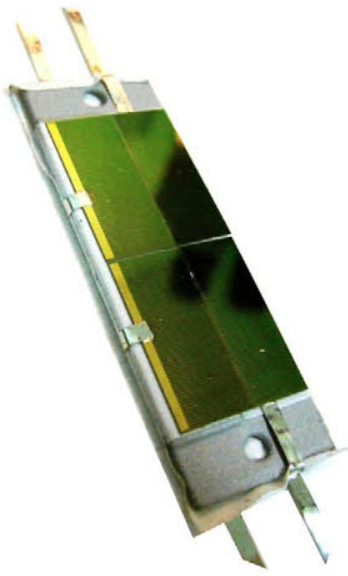

(c)

Figure 3. (a, b) TPV modules manufactured according to approach 1 (M1-M6) mounted on a hexagonal water-cooled heat-sink. Note that the hexagonal heat-sink is divided in two parts, each hosting three TPV modules. Each side can move with respect to each other by means of a hinge, which allows opening of the TPV cavity during operation to check whether the emitter is being properly heated.

(c) TPV module manufactured according to approach 2. 
Table I. Description of the TPV modules developed according to approaches 1 and 2.

\begin{tabular}{|c|c|c|c|c|c|c|}
\hline Module ID & $\begin{array}{l}\text { Assembling } \\
\text { approach }\end{array}$ & $\begin{array}{l}\text { Substrate } \\
\text { material }\end{array}$ & $\begin{array}{l}\text { Substrate } \\
\text { metallization }\end{array}$ & $\begin{array}{l}\text { Back-side } \\
\text { bonding }\end{array}$ & $\begin{array}{l}\text { Shingling } \\
\text { solder }\end{array}$ & $\begin{array}{l}\text { Front } \\
\text { contact }\end{array}$ \\
\hline M1 & 1 & MACOR & $\mathrm{Cr} / \mathrm{Ag}$ & BiSn solder & $\operatorname{SnAg}$ & PGW \\
\hline $\mathrm{M} 2$ & 1 & $\mathrm{Cu}+$ Corr-Paint & $\mathrm{Cr} / \mathrm{Ag}$ & BiSn solder & $\operatorname{SnAg}$ & PGW \\
\hline $\mathrm{M} 3$ & 1 & $\mathrm{Cu}+$ Corr-Paint & $\mathrm{Cr} / \mathrm{Ag}$ & BiSn solder & $\operatorname{SnAg}$ & PGW \\
\hline M4 & 1 & $\mathrm{Cu}+$ Corr-Paint & $\mathrm{Cr} / \mathrm{Ag}$ & BiSn solder & $\operatorname{SnAg}$ & PGW \\
\hline M5 & 1 & $\mathrm{Cu}+$ Corr-Paint & $\mathrm{Cr} / \mathrm{Ag}$ & BiSn solder & $\operatorname{SnAg}$ & PGW \\
\hline M6 & 1 & MACOR & $\mathrm{Cr} / \mathrm{Ag}$ & BiSn solder & SnAg & Cu tape* \\
\hline$M 7$ & 1 & MACOR & $\mathrm{Cr} / \mathrm{Ag}$ & BiSn solder & $\mathrm{SnAg}$ & Cu tape* \\
\hline M8 & 2 & $\mathrm{BN}$ & - & LOCTITE 315 & $\operatorname{SnAg}$ & Cu tape** \\
\hline M9 & 2 & Shapal-M & - & LOCTITE 315 & $\operatorname{SnAg}$ & Cu tape** \\
\hline M10 & 2 & $\mathrm{BN}$ & - & LOCTITE 315 & $\mathrm{SnAg}$ & Cu tape $* *$ \\
\hline M11 & 2 & $\mathrm{BN}$ & - & LOCTITE 315 & $\operatorname{SnAg}$ & Cu tape** \\
\hline $\mathrm{M} 12$ & 2 & $\begin{array}{l}\text { Cu + Corr-Paint } \\
\text { (without } \\
\text { grooves) }\end{array}$ & - & Bond-Ply 100 & $\mathrm{SnAg}$ & Cu tape ${ }^{*}$ \\
\hline M13 & 2 & Shapal-M & - & Bond-Ply 100 & $\mathrm{SnAg}$ & Cu tape** \\
\hline M14 & 2 & $\mathrm{BN}$ & - & LOCTITE 315 & SnAg & Cu tape** \\
\hline
\end{tabular}

LOCTITE 315 is a thermally conductive adhesive, and Bond-Ply 100 is a two-side thermally conductive and pressure-sensitive adhesive tape.

*Soldered along the full bus-bar of the cells.

* * Soldered in the center of the bus-bar (transversal).

to host the copper tapes (Figure 2). Figure 3 shows a picture of a module manufactured according to this approach.

Note that in approach 1 , electrically conductive traces are required on the substrate to perform the external electrical contacts (Figure 2). These metallic traces consist of a $\mathrm{Cr} / \mathrm{Ag}$ layer deposited using the thermal physical vapour deposition (PVD) technique, forming three electrically isolated parts. The very thin layer of $\mathrm{Cr}(5-7 \mathrm{~nm})$ is used as an adherent precursor between the ceramic substrate and the Ag layer, which is used because of its very high electrical conductivity. Then, because the evaporated Ag layer is too thin $(200-300 \mathrm{~nm})$, a final electrolytic silver layer was grown in order to increase the electrical conductivity of the interconnecting traces. Table I summarizes the characteristics of all the developed TPV modules.

Each TPV module has been tested using a constantvoltage multi-flash system [45]. Figure 4 shows the $I-V$ curve of the TPV module M12, in which the voltage and current addition with respect to the individual cells is demonstrated. Figures 5 and 6 show the $V_{\mathrm{OC}}$ and the FF, respectively, of several TPV modules, and Figure 7 shows the TPV module efficiencies, in arbitrary units. Note that a relatively high FF of $65-70 \%$ has been obtained for the approach 2 modules for current densities up to $2 \mathrm{~A} / \mathrm{cm}^{2}$. However, we note that approach 1 provides notably lower FF and efficiency than approach 2, especially at high current densities. We have identified that this fact is attributed to a bad behavior of the back-side contact in the modules manufactured according to approach 1 . In this regard, we have taken thermal images resulting when a relatively high current ( $3 \mathrm{~A}$ ) is passing through these TPV modules, and we have noted a great non-uniform temperature in all of

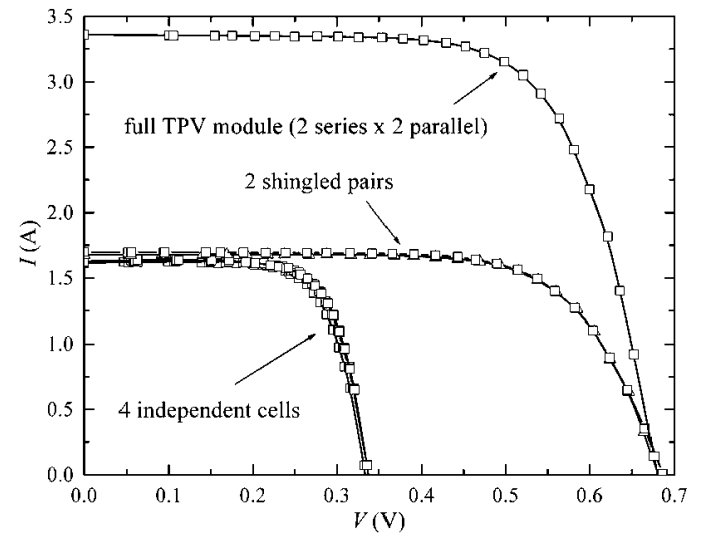

Figure 4. $-V$ curves of a full TPV module (M12) made up of four germanium cells in which two pairs of shingled (seriesconnected) cells have been connected in parallel.

them indicating that either (or both) the ohmic heating (series resistance losses) and/or the thermal conductivity is not uniform throughout the back contact. Besides, after desoldering some modules, we observed the lifting off of the silver metalization from the substrate, which points out bad adhesion of the electrolytic silver layer to the ceramic substrate.

\section{THE SUNLIGHT CONCENTRATOR SYSTEM}

The sunlight concentrator comprises a primary Fresnel lens of $60 \times 60 \mathrm{~cm}$ and a secondary meniscus lens and was mounted on a two-axis sun-tracking system. This design, 


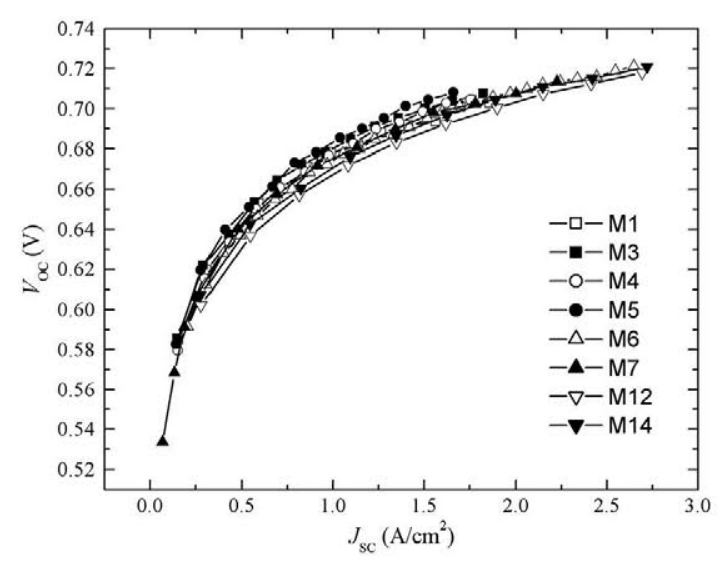

Figure 5. Open-circuit voltage of some of the manufactured TPV modules, as a function of the short-circuit current density.

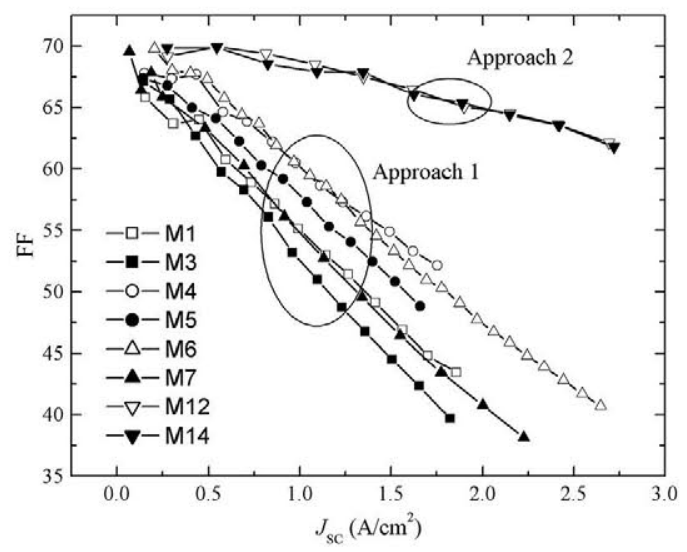

Figure 6. Fill factor of some of the manufactured TPV modules, as a function of the short-circuit current density.

despite not being optimal to achieve high concentrations with high efficiency, has been elected because it leads to simpler structural designs compared with the use of reflective concentrators.

To characterize this concentrator, we have measured the fraction of the total input energy that lies within a specific diameter at the focus plane. Each diameter represents a different geometrical concentration factor, and the

\footnotetext{
${ }^{3}$ Because the PHIR-L30A-SH-V1 sensor not only detects the normal incidence irradiance (direct irradiance) but also the global irradiance, the measurements were corrected taking into account the global and diffuse irradiance detected by two piranometers: the Kipp \& Zonen CM11 (for diffuse irradiance measurement) and the EPPLEY PS (for global irradiance measurement).

${ }^{4}$ It is important to note that during the measurements, we noted that when placing an aluminum sheet (without hole) on top of the thermal sensor, there was no detection of radiative power. It discards the possibility of detecting the infrared emission of the aluminum mask, heated by the concentrated sunlight.
}

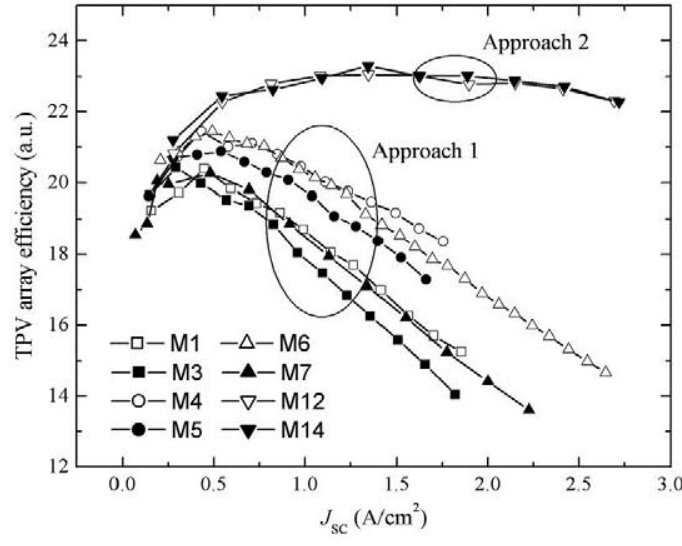

Figure 7. TPV modules efficiency (in arbitrary units) as a function of the short-circuit current density.

concentrator efficiency is given by the total power falling within that diameter to the incident total sun-power ratio.

To measure the irradiance at the focus plane, we have used the broadband thermal detector PHIR-L30A-SH-V1, with a spectral detection range from 0.19 to $20 \mu \mathrm{m}$, which detects up to $30 \mathrm{~W}$ of radiative power. Because the expected light power at the focus plane of our concentrator system is about $300 \mathrm{~W}$, a metallic mask is used at the entrance of the concentrator system to attenuate the light power impinging the detector. The mask consist of a $60 \times 60 \mathrm{~cm}$ aluminum sheet (matching the Fresnel lens area) with 36 holes (six lines and six rows) of $2.91 \mathrm{~cm}$ diameter, each one separated with $10 \mathrm{~cm}$ between each other. It represents an transmittance factor of $6.65 \%$, which allows reducing the power range from 300 to $20 \mathrm{~W}$. Finally, the sunlight power distribution at the focus plane is obtained by using a set of hole-masks with different diameters placed on top of the broadband thermal sensor.

Figure 8 shows the measured concentrator efficiency as a function of the absorber hole diameter. The sun irradiance at the entrance of the concentrator was measured using two different sensors: a Kipp \& Zonen CH1 normal incidence pyrheliometer and the PHIR-L30A-SH-V1 detector. ${ }^{3}$ In this regard, the error bars shown in Figure 8 represent the difference in using the two sensors. Two configurations, with and without secondary meniscus lens, were tested. Besides, the measurements were performed at different positions (A, B, and C), which represent different distances from the detector to the Fresnel lens, ranging from $72 \mathrm{~cm}$ (position A) to $73 \mathrm{~cm}$ (position C). ${ }^{4}$

From Figure 8, we note that a large hole diameter is required to maximize the concentrator efficiency and that the use of the secondary lens provides higher efficiency for small hole diameters. On the other hand, the use of a meniscus lens provides a slightly lower efficiency for higher hole diameter because of the transmission losses at that lens.

Despite the fact that the concentrator efficiency increases with the hole diameter, it must be noted that the optimum diameter must fulfill a trade-off between the 


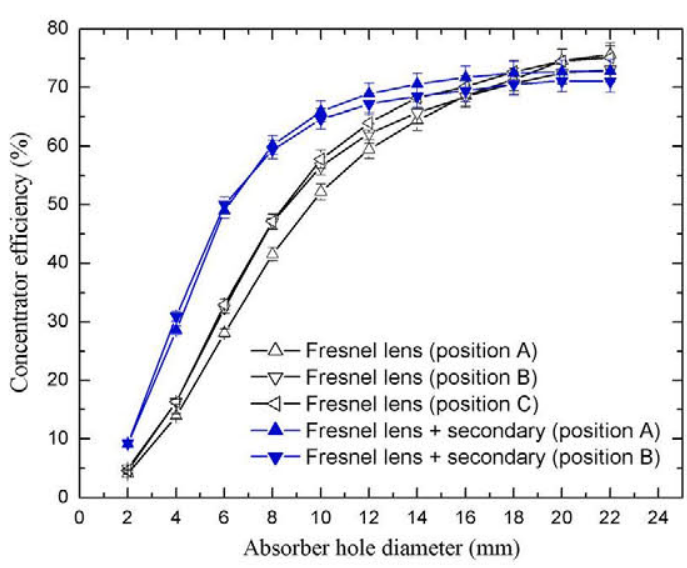

Figure 8. Concentrator efficiency (measured using aluminum metallic masks) as a function of the absorber hole diameter for two configurations: with and without secondary condenser lens. The efficiency has been measured at different distances from the Fresnel lens (positions A, B, and C).

concentrator losses (which decreases with the absorber hole diameter) and the absorber emission losses (which increases with the absorber hole diameter). In this regard, a hole diameter of about $12 \mathrm{~mm}$ (which represents a geometrical concentration factor of $3183 \mathrm{X}$ with a concentrator efficiency of $65-70 \%$ ) must be chosen because higher diameters do not represent considerable concentrator efficiency improvement.

\section{ESTIMATION OF THE EMITTER TEMPERATURE}

The measurement of the emitter temperature in a STPV system is a very challenging task. This is because optical pyrometers cannot be used either because of the spectrally dependent emissivity of the emitter surface or the undesirable reflections coming from other light sources that are unavoidable outdoors. Therefore, thermocouples must be used in most of the cases. In this regard, the precise location of the thermocouple is critical, and, in most of the cases, just an orientative temperature can be provided because of the temperature gradients appearing in the emitter. In this section, we describe an attempt to measure the temperature of the cylindrical emitters used in our STPV system. We present both the estimated temperature as well as the lessons learned from this process that can be of interest for the reader in order to understand the inherent difficulties of temperature measurement.

We have used two kinds of absorber/emitter components. First, graphite emitters were used to experimentally estimate the emitter temperature by means of a thermocouple. Second, using these results, we estimate the temperature of tungsten emitters, which were used to operate the full STPV system.

\subsection{Graphite emitters}

Several graphite emitters with different diameters and lengths were developed to estimate the emitter temperature under concentrated sunlight. Graphite material was selected because of its very high sublimation point $\left(3650-3700^{\circ} \mathrm{C}\right)$ and because it is easily machinable, which allows us to manufacture our own ad hoc emitter shapes. Besides, note that the very high emissivity of graphite allows estimating the lower bound for the achievable temperature, using this specific concentrator system, of an emitter made of other materials with a lower emissivity. ${ }^{5}$

A C-type thermocouple (model Omega T5R-005-12) is introduced inside the absorber cavity by means of a two-hole ceramic (alumina) insulator (model Omega TRX-164116-6), which at the same time plays the role of the emitter holder. The thermocouple signal was acquired using a programmable temperature meter (model Omega DPI32-C24), which transmits the temperature reading via $\mathrm{RS}-232$ to a $\mathrm{PC}$, which allows conducting programmed lectures during long periods.

Figure 9(a) shows several of these emitters operated under concentrated sunlight. Note that, in general, the temperature is not uniform along the emitter walls. In fact, the degree of non-uniformity depends on the emitter dimensions. For instance, emitter $10(L / R=5.3)$ shows a much more uniform temperature distribution than emitter $8(L / R=2)$. It illustrates how it is possible to obtain a more uniform emitter temperature profile just by tuning the emitter dimensions. It is because for some specific emitter shape, the distribution of the sunlight absorption along the absorber cavity walls allows each infinitesimal portion of the emitter to be in thermal equilibrium, without the necessity of lateral thermal conduction.

Figure 10 shows the acquired thermocouple temperature (dots) at $800 \mathrm{~W} / \mathrm{m}^{2}$ sun irradiance conditions of 11 graphite emitters as a function of the emitter-to-absorber area ratio of the emitter $\left(A_{\text {emit }} / A_{\text {abs }}=1+2 L / R\right)$. Besides, the emitter temperature that results from the solution of an energy balance at the emitter/absorber (assuming only a radiative heat transfer mechanism) is superimposed. The calculations were performed for two limiting cases: first, assuming a graphite emissivity of 0.9 and an underestimated quartz transmittance of 0.9 , which leads to the lowest emitter temperature; and second, assuming a graphite emissivity of 0.75 and an overestimated quartz transmittance of 0.99 , which leads to the highest emitter temperature. The areas noted as "energy balance" in Figure 10 represent all the calculated emitter temperatures bounded by both limiting cases. In these calculations, we have taken into account that each diameter corresponds to a different

\footnotetext{
${ }^{5} \mathrm{~A}$ diffuse reflectivity of 0.25 was measured at room temperature for a broad range of wavelengths (300-1700 nm). It means that the emissivity at room temperature is 0.75 . Besides, the emissivity of graphite is expected to increase with the temperature, which means that a very high emissivity (from 0.75 to 0.9 ) is expected.
} 


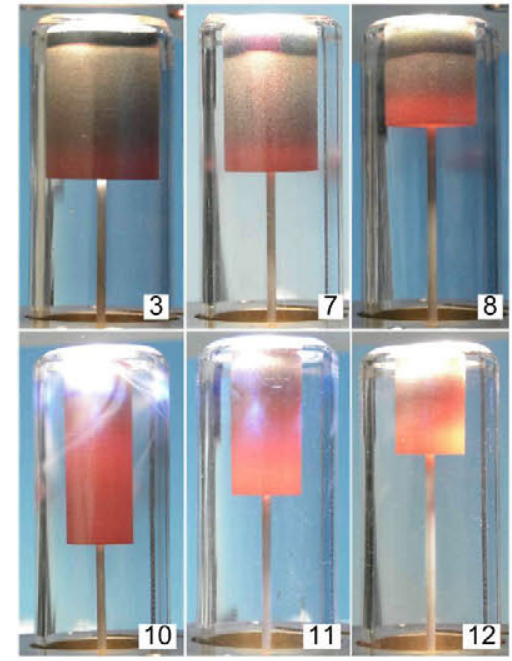

(a)

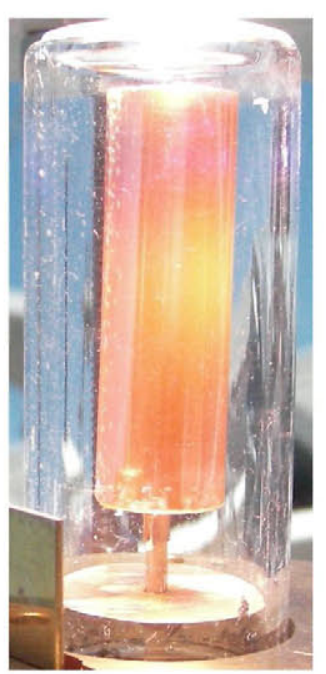

(b)

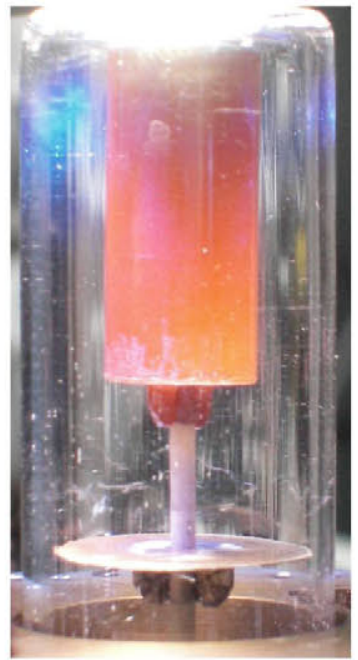

(c)

Figure 9. (a) Six of the graphite emitters tested under concentrated sunlight, (b) pure-tungsten emitter ( $36 \mathrm{~mm}$ length and $12 \mathrm{~mm}$ diameter) operated under concentrated sunlight, (c) tungsten emitter ( $25 \mathrm{~mm}$ length and $12 \mathrm{~mm}$ diameter) coated with $\mathrm{HfO}_{2}$ operated under concentrated sunlight.

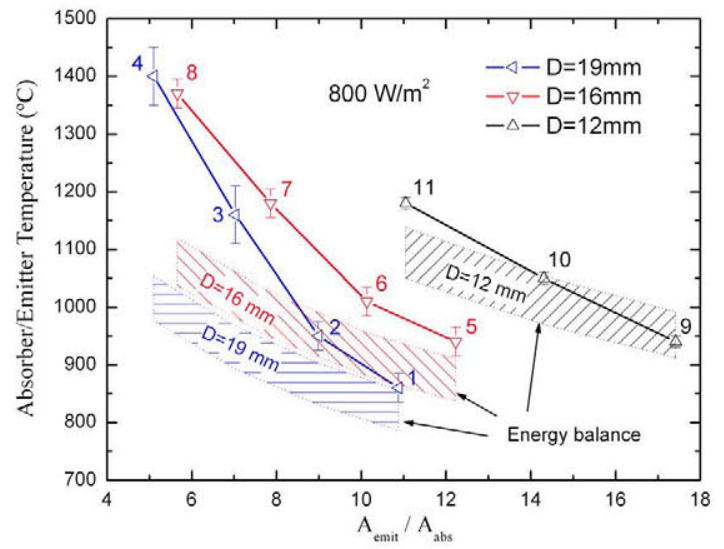

Figure 10. Experimental versus modeled absorber emitter/temperature of the 11 graphite absorbers tested as a function of the emitter-to-absorber area ratio, that is, $A_{\text {emit }} / A_{\text {abs }}=\left(2 \pi R L+\pi R^{2}\right)=$ $\pi R^{2}$ for an irradiance level of $800 \mathrm{~W} / \mathrm{m}^{2}$.

concentrator efficiency (Figure 8). For instance, $D=12 \mathrm{~mm}$ represents $C=3183 \mathrm{X}$ and $\eta_{\text {conc }} \approx 67 \%, D=16 \mathrm{~mm}$ represents $C=1790 \mathrm{X}$ and $\eta_{\text {conc }} \approx 71 \%$, and $D=19 \mathrm{~mm}$ represents $C=1270 \mathrm{X}$ and $\eta_{\text {conc }} \approx 72 \%$.

Note that the experimental thermocouple measurement surpasses the calculated temperature, especially for low $A_{\text {emit }} / A_{\text {abs }}$ (Figure 10 ). In this regard, we must note that in order to ensure the correct temperature measurement, the thermocouple should be completely surrounded by a uniform temperature cavity. However, in this case, none of these conditions are accomplished: first, because the absorber shows a non-uniform temperature distribution (Figure 9(a)); and second, because the absorber cavity is partially open, and the direct absorption of sunlight could lead to overheating of the thermocouple. Both are in agreement with the especially higher thermocouple temperature achieved for low $A_{\text {emit }} / A_{\text {abs }}$ emitters, which present the higher fraction of open area of the absorber cavity and the more pronounced non-uniform temperature distribution.

The overheating of the thermocouple can be corroborated by looking at the pictures shown in Figure 9(a). For instance, we note that emitters 3 and 7 present a lower color-temperature than emitter 11 . However, the thermocouple temperature was more or less the same for these three emitters (Figure 10). Another evidence is the fact that the thermocouple temperature for the emitters with $D=16 \mathrm{~mm}$ and $D=19 \mathrm{~mm}$ approach each other for very low $A_{\text {emit }} / A_{\text {abs }}$ (emitters 4 and 8 ). It means that in those cases, the graphite temperature is not affecting the thermocouple reading but only the sunlight directly impinging the thermocouple, which is mostly the same in both cases.

In contrast, the calculated temperature matches relatively well with the experimental data for high $A_{\mathrm{emit}} / A_{\mathrm{abs}}$, especially for emitters 9 and 10 . It is a consequence of two reasons: first, because of the larger view factor between the thermocouple and the absorber walls and second, because of the more uniform temperature profile of these emitters (Figure 9(a)). Besides, we remind the reader that the calculated temperature is obtained assuming only radiative heat exchange at the emitter. Therefore, the good agreement between experimental and calculated data suggests that the convection and conduction heat transfer mechanisms are not relevant.

\subsection{Tungsten-based emitters}

Several tungsten emitters were manufactured in the frame of the FULLSPECTRUM project by the Ioffe Physico-Technical Institute (Russia) $[34,35]$. They consisted of a $0.06-\mathrm{mm}$ thick 
tungsten foil rolled into a cylinder $12 \mathrm{~mm}$ in diameter, whose edges were welded by means of resistance welding through a thin pad made of tantalum. Afterwards, some of these emitters were sent to Fraunhofer-ISE for the $\mathrm{HfO}_{2}$ anti-reflective coating (ARC) using the PVD technique, and finally, they were tested under concentrated sunlight conditions at IESUPM (Figure 9(b and c)).

Because of the difficulty to drill tungsten, we were not able to introduce a thermocouple within the absorber

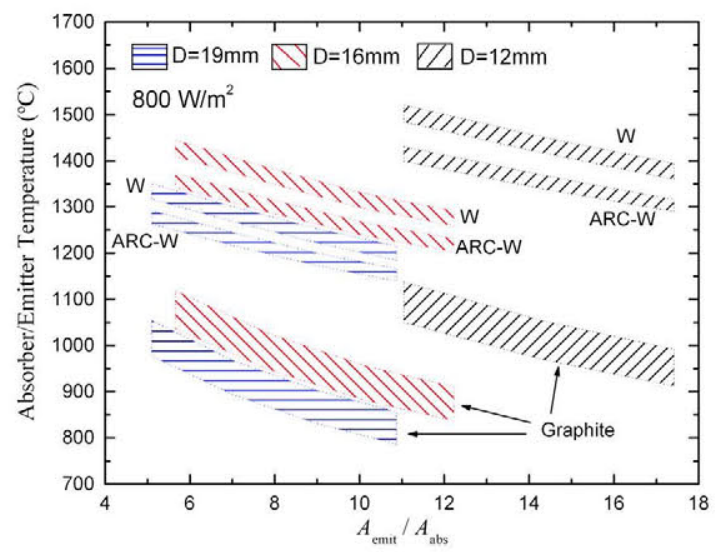

Figure 11. Estimated temperature of different emitter/absorber configurations. cavity, and therefore temperature measurements were not carried out for these emitters. However, shown in Figure 11 is the calculated temperature that would result in the case of using either pure-tungsten (W) or ARC-tungsten (ARC-W) emitter. Note that higher temperatures are obtained because of the lower emissivity of tungsten. Besides, slightly lower temperature is obtained for the $\mathrm{HfO}_{2}$ coated emitters because of its higher emissivity at short wavelengths. In any case, temperatures in the range of $1300-1500{ }^{\circ} \mathrm{C}$ are expected for tungsten-based emitters with $D=12 \mathrm{~mm}$.

\section{OUTDOOR TESTS OF THE COMPLETE STPV SYSTEM}

The full STPV system was mounted on a two-axis sun tracker system at the roof of the IES-UPM (Figure 12). During the mounting process, we aligned the different optical components (primary and secondary lenses) to achieve the maximum output power, corresponding to the maximum emitter temperature. The irradiance data were acquired by a pyrheliometer located just a few meters away from the system. Two tests were performed: in the first one, we used the TPV modules manufactured according to approach 1 (Figure 3), and in the second one we used the TPV modules manufactured according to approach 2 (Figure 3(c)). In both cases, we used
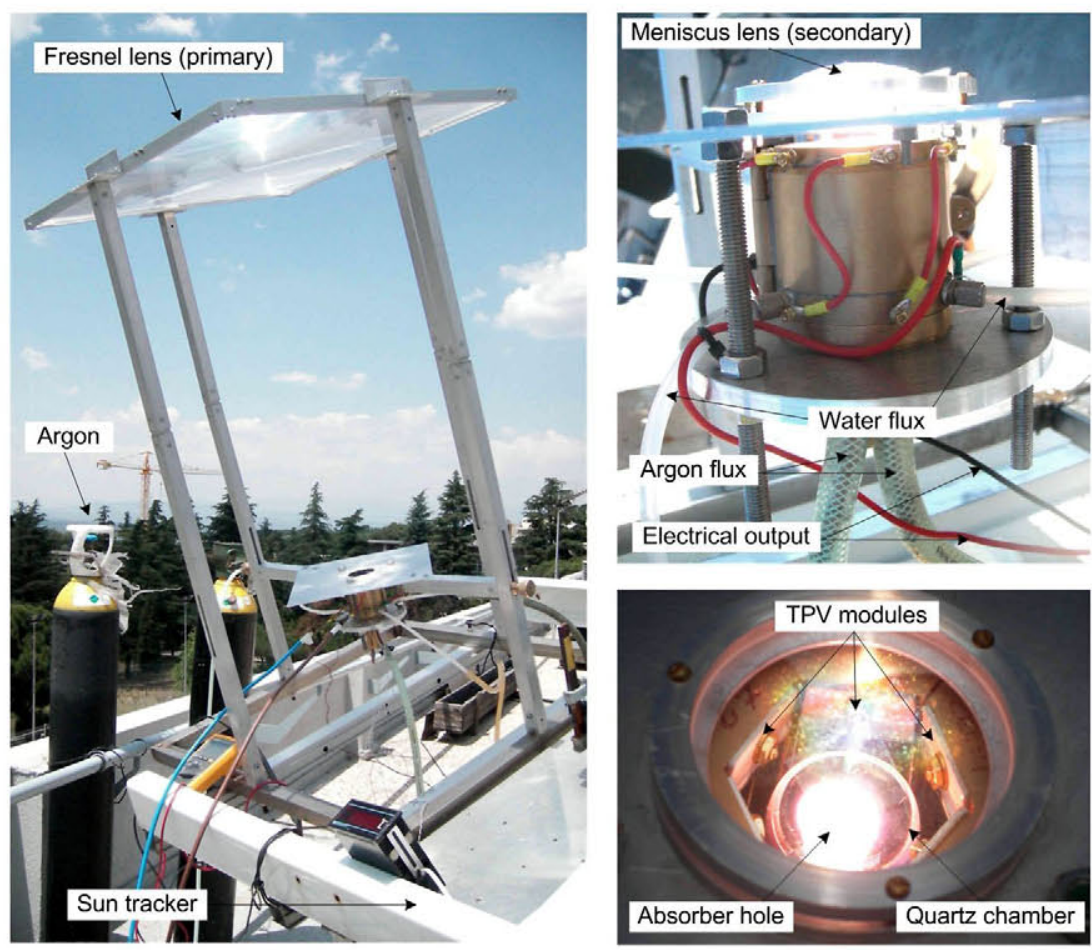

Figure 12. Full TPV generator operated under concentrated sunlight. 
cylindrical ARC-W emitters $25 \mathrm{~mm}$ in length and $12 \mathrm{~mm}$ in diameter. The characterization consisted of measuring the $I-V$ curve (using a Keithley 2602 four-probe source/ meter) of both the complete STPV module (first test) as well as of the independent shingled pairs comprising each module (second test).

\subsection{First test}

In this test, the $I-V$ curves of the full array comprising the TPV modules M1-M6 (manufatured according to the approach 1) were acquired. The system was tested during a full day to evaluate the effect of different irradiance conditions on the system output power. Figure 13 shows, for the full TPV generator, the short-circuit current density $\left(J_{\mathrm{SC}}\right.$, i.e., the current density delivered by the module when it is biased at $V=0 \mathrm{~V})$ and the photocurrent density $\left(J_{\mathrm{L}}\right.$, i.e., the net current density internally generated in the module because of external illumination). In the ideal case, $J_{\mathrm{SC}}$ equals $J_{\mathrm{L}}$ because at $V=0 \mathrm{~V}$ all the generated current is delivered to the external circuit. However, if either the light intensity impinging the cells or the series resistance of the module are too high, some of the cell $p / n$ junctions could be biased, and therefore part of the generated current would be internally consumed by means of recombination. This could lead to a case in which $J_{\mathrm{SC}}<J_{\mathrm{L}}$. In that case, the $J_{\mathrm{L}}$ value must be measured at negative biasing of the TPV array (in our case, $-1 \mathrm{~V}$ ). Note that in the case of seriesconnected modules with non-uniform current generation, $J_{\mathrm{L}}$ represents the lowest current generated among all the series-connected modules.

The first notable effect from Figure 13 is that $J_{\mathrm{L}}$ and $J_{\mathrm{SC}}$ have a supra-linear dependence on the irradiance level. It is due to the better spectral matching between the emitter spectrum and the TPV cells spectral response at higher irradiance levels (i.e., higher emitter temperatures). Note that because of this supra-linear dependence, if both the open-circuit voltage and the FF had a soft variation with the irradiance level, the conversion efficiency (given by the output electrical power: $J_{\mathrm{SC}} \cdot V_{\mathrm{OC}} \cdot F F$, to incident sun-power ratio) would increase with the irradiance level.

However, both the $V_{\mathrm{OC}}$ (Figure 14) and the FF (Figure 15) decrease with the irradiance level. The deterioration of the $V_{O C}$ points out the increment of the cells' averaged temperature. In this regard, Figure 14 shows that the calculated averaged cell temperature reaches $90^{\circ} \mathrm{C}$ $\left(70^{\circ} \mathrm{C}\right.$ above the cooling temperature of $\left.20^{\circ} \mathrm{C}\right)$ for $900 \mathrm{~W} / \mathrm{m}^{2}$. This temperature is calculated through the variation of the $V_{\mathrm{OC}}$ with respect to the one at room temperature conditions by means of the $\beta$ parameter. ${ }^{6}$ On the other

\footnotetext{
${ }^{6}$ The $\beta$ parameter accounts for the variation of the open-circuit voltage with respect to a cell temperature variation. For the germanium cells used and short-circuit currents from 0.1 to $1 \mathrm{~A} /$ $\mathrm{cm}^{2}$, a $\beta$ parameter from -1.56 to $-1.77 \mathrm{mV} /{ }^{\circ} \mathrm{C}$ has been measured using a Peltier temperature controller and a constantvoltage multi-flash tester.
}

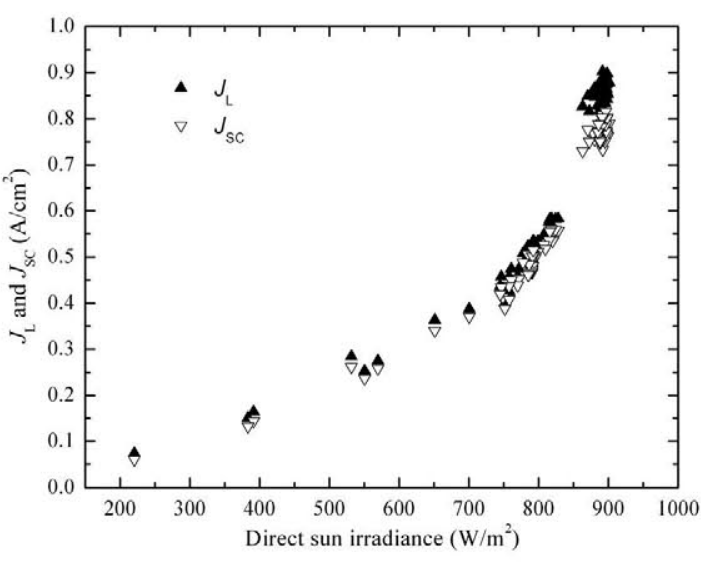

Figure 13. The short-circuit current density $\left(J_{S C}\right)$ and the photocurrent density $\left(J_{L}\right.$, measured at negative biasing of the TPV array) of the full TPV array (comprising the TPV modules M1-M6) under real operation conditions.

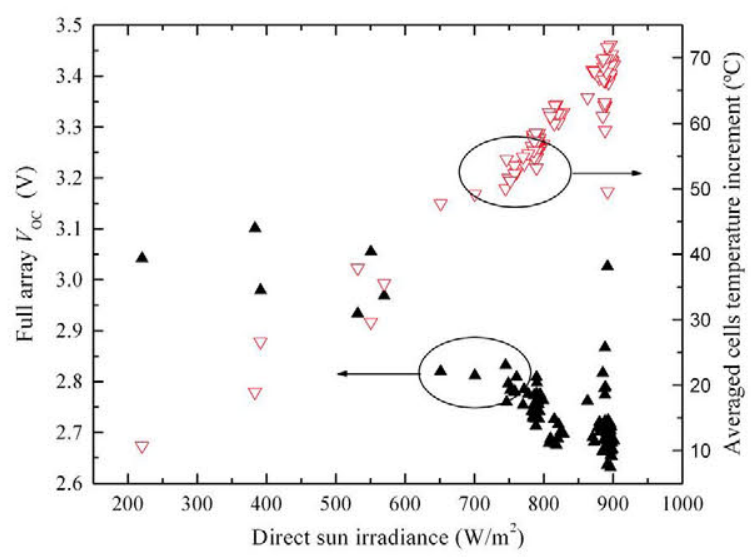

Figure 14. The open-circuit voltage $\left(V_{O C}\right)$ and the calculated cell averaged temperature increment of the full TPV array (comprising TPV modules M1-M6) under real operation conditions.

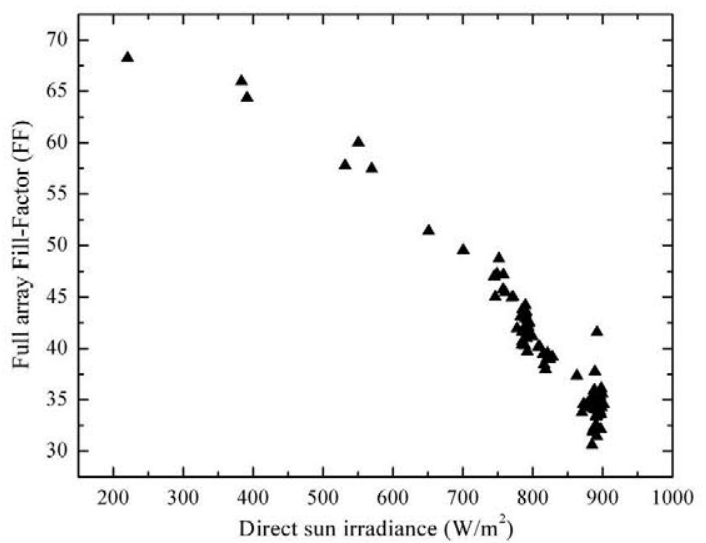

Figure 15. The fill factor (FF) of the full TPV array (comprising the TPV modules M1-M6) under real operation conditions. 
hand, the FF degradation (Figure 15) is not only attributed to the heating of the cells but also to the series resistance of the array (especially relevant for modules M1-M6).

Because of these reasons, the measured STPV system efficiency (Figure 16) is extremely low (not exceeding $0.8 \%$ ), and the system efficiency, which was expected to increase with the irradiance level (because of the supralinear dependence of the $J_{\mathrm{SC}}$ ), is found to be more or less the same for every irradiance level. Besides, the electrical output power rarely exceeds $2.5 \mathrm{~W}$, which represents an averaged electrical power density of only $67.2 \mathrm{~mW} / \mathrm{cm}^{2}$.

Figure 16 also shows the overall system efficiency that would be achieved if the TPV generator had a constant fill factor of $65 \%$ and the cells were operated at room temperature $(300 \mathrm{~K})$. We observe that, in this case, the STPV efficiency would increase with the irradiance level, as expected, and the overall system conversion efficiency would surpass $2 \%$. Besides, the very high abrupt increment of the conversion efficiency with the irradiance level suggests that the improvement of the concentrator efficiency would also imply a notable increment of the conversion efficiency. Therefore, we can estimate that efficiencies above $5 \%$ are achievable just improving the concentrator system, the TPV cell cooling, and the electrical connection between the cells within the TPV module.

These predictions match with our previous theoretical analysis of real STPV systems [5], where we predicted efficiencies slightly above $5 \%$ for a similar system configuration. In that analysis, we also stated that efficiencies above $10 \%$ could be achieved with the incorporation of improved devices (emitter, cells, etc.) and the improvement of the TPV cavity design.

\subsection{Second test}

In the second test, we used modules M8-M13 (manufactured accoring to the approach 2). These modules allow for the external connection to every shingled pair (12 in total) within each TPV module. It allows for a more precise

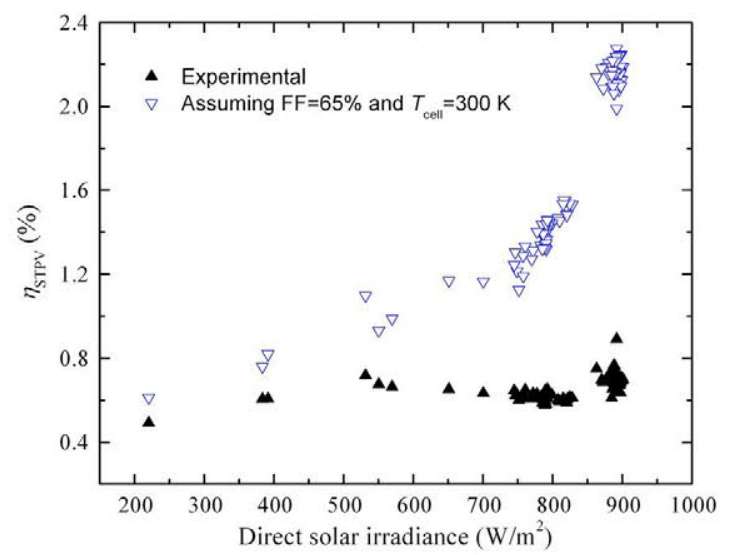

Figure 16. The overall sun-to-electricity conversion efficiency and the output electrical power of the full STPV system under real operation conditions. characterization of the uniformity of the electrical generation in the TPV generator. For that purpose, we will consider the full array divided on two rings of cells: The bottom ring of cells comprises six shingled pairs noted as $\mathrm{M} X$-B ( $X$ being the module number, from 1 to 6 ), and the top ring of cells comprises the shingled pairs noted as $\mathrm{M} X-\mathrm{T}$.

Figure 17 shows the $I-V$ curves of every shingled pair for an irradiance level of $750-800 \mathrm{~W} / \mathrm{m}^{2}$, and Table II summarizes the results. First, the great photocurrent dispersion between the shingled pairs is noted. As expected, such scattering is more relevant in the axial direction (accounting for the difference between the modules $M X-T$ and $\mathrm{M} X$-B) than in the radial one. In this sense, note that because the emitter is located at the top of the quartz chamber (slightly above the top ring of cells), the cells comprising the bottom ring of cells are less illuminated and provide lower photocurrent densities. It justifies the parallel connection of the cells in that direction. However, there is also a significant dispersion in the radial direction, which accounts for additional current mismatch losses.

On the other hand, despite the higher $J_{\mathrm{SC}}$ of the $\mathrm{M} X$ - $\mathrm{T}$ modules, their $V_{\mathrm{OC}}$ is lower than that of the $\mathrm{M} X$-B modules. It is because of the higher cell temperature for the MX-T modules. In this sense, Table II shows the estimated cell temperatures, obtained from the difference in the opencircuit voltage measured in real conditions and that measured at room temperature in a flash tester. The calculated cell temperature is found to be in the range of $50-60^{\circ} \mathrm{C}$ (30- $40^{\circ} \mathrm{C}$ above the cooling temperature of $20^{\circ} \mathrm{C}$ ) for the $\mathrm{MX}$-B modules and $80-100^{\circ} \mathrm{C}$ for the $\mathrm{MX}$ - $\mathrm{T}$ ones. It must be taken into account that the pair M12-B reaches a much higher temperature than the rest of pairs with a similar photocurrent density. This effect accounts for the bad thermal contact between the cell and the substrate in that module. ${ }^{7}$ Besides, we noted that the pair M12-T was shunted, which is probably due to the overheating of the cells within that pair, which is expected to be at higher temperature than the M12-B pair because it is placed in

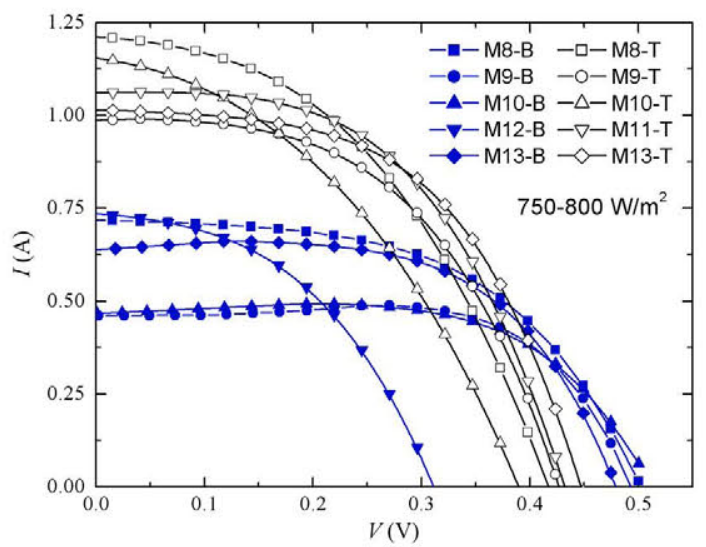

Figure 17. $L V$ curves of the independent shingled pairs comprising the full STPV module. 
Table II. Output electrical characteristics of the shingled pairs comprising the full TPV array.

\begin{tabular}{|c|c|c|c|c|c|c|c|c|}
\hline \multirow[b]{2}{*}{ Module } & \multicolumn{4}{|c|}{ Real measurements } & \multicolumn{4}{|c|}{ Flash measurements $\left(25^{\circ} \mathrm{C}\right)$} \\
\hline & $J_{\mathrm{SC}}\left(\mathrm{mA} / \mathrm{cm}^{2}\right)$ & $V_{O C}(\mathrm{mV})$ & $\mathrm{FF}$ & $P_{\mathrm{MPP}}(\mathrm{mW})$ & $V_{O C}(\mathrm{mV})$ & $\mathrm{FF}$ & $P_{\mathrm{MPP}}(\mathrm{mW})$ & $\Delta T 1^{\circ} \mathrm{C}$ \\
\hline M8-B & 463 & 503.1 & 53.7 & 194.1 & 629.5 & 63.2 & 285.6 & 38.6 \\
\hline M9-B & 298 & 493.2 & 70.6 & 160.8 & 611.0 & 70.7 & 199.4 & 35.2 \\
\hline M10-B & 301 & 514.4 & 65.0 & 156.4 & 615.4 & 67.7 & 194.7 & 30.2 \\
\hline M12-B & 475 & 311.6 & 45.5 & 104.4 & 635.2 & 68.2 & 319.2 & 99.0 \\
\hline M13-B & 410 & 479.8 & 61.8 & 188.8 & 631.7 & 71.7 & 288.0 & 46.1 \\
\hline M8-T & 783 & 417.5 & 44.3 & 224.6 & 661.3 & 65.0 & 522.3 & 76.4 \\
\hline M9-T & 636 & 427.4 & 51.8 & 218.4 & 653.6 & 71.7 & 461.8 & 70.2 \\
\hline M10-T & 747 & 390.0 & 40.0 & 180.6 & 663.6 & 66.5 & 510.4 & 85.6 \\
\hline M11-T & 683 & 432.5 & 52.8 & 242.1 & 654.7 & 70.2 & 487.1 & 69.2 \\
\hline M13-T & 654 & 447.9 & 54.1 & 245.6 & 657.5 & 69.1 & 460.7 & 65.1 \\
\hline$P_{\text {TOTAL }}(\mathrm{W})$ & \multicolumn{4}{|c|}{$1.92(10$ modules out of 12$)$} & \multicolumn{3}{|c|}{3.73 (10 modules out of 12$)$} & \\
\hline$\eta_{\mathrm{STPV}}(\%)$ & \multicolumn{4}{|c|}{$0.73-0.85$} & \multicolumn{3}{|c|}{$1.55-1.66$} & \\
\hline$\eta_{\mathrm{STPV}}(\%)^{*}$ & \multicolumn{4}{|c|}{-} & \multicolumn{3}{|c|}{$2.6-4.1$} & \\
\hline
\end{tabular}

The STPV system is operated under $750-800 \mathrm{~W} / \mathrm{m}^{2}$ sun irradiance conditions.

*Calculated without considering the optical concentrator losses and assuming the cells at $25^{\circ} \mathrm{C}$

the top ring of the array, leading to a possible melting of the soldered contact.

The STPV efficiency, calculated from the addition of the electrical output power generated by the independent shingled pairs, results to be around $0.8 \%$, and the averaged electric power densities is about $62 \mathrm{~mW} / \mathrm{cm}^{2}$. Note that this result corresponds to irradiance levels of $750-800 \mathrm{~W} / \mathrm{m}^{2}$ and that, in the first test, an efficiency of about $0.6 \%$ was obtained for those irradiance levels (Figure 16). The slightly higher efficiency obtained in this test can be attributed to the higher FF of the modules M8-M13 and also to the dispersion losses, which are not included in this new analysis.

\section{FUTURE EFFICIENCY PREDICTION}

In the previous section, we have seen that efficiencies of above $2 \%$ are possible by just improving the cells cooling and the electrical connection between the cells in the array. Besides, we have seen that efficiencies above $5 \%$ are plausible, improving also the sunlight concentration system. These predictions are exclusively based on experimental evidences. However, the experiments presented in this paper are useless when predicting the effect on the system performance of more sophisticated improvements, for instance, the improvement of the photon recycling process within the optical cavity.

In this section, we use the theoretical models presented in $[5,46]$ to predict the performance of cylindrical STPV systems with improved photon recycling system. This analysis assumes that both the emitter and the cells are isothermal

\footnotetext{
${ }^{7}$ Looking at Table I, we see that in this module the substrate has no groves to host the back-side copper tape, and consequently, the cells are not in good thermal contact with the substrate.
}

and diffuse cylinders with the same length $(L)$ and different radii ( $R_{\mathrm{E}}$ and $R_{\mathrm{C}}$, respectively) and that there are no convective neither conductive losses in the emitter. We have conducted simulations for two scenarios: scenario 1 considers Ge TPV cells without BSR, tungsten emitters, and a relative distance between the cells and the emitter $\left(\left(R_{\mathrm{C}}-R_{\mathrm{E}}\right) / R_{\mathrm{C}}\right)$ of 0.6 . In contrast, scenario 2 incorporates some improvements: Ge cells with back-side reflector (BSR), ARC-W emitters, and a relative distance between the emitter and the cells of 0.1 (much closer). Besides, scenario 2 considers lateral reflectors that minimize the radiative losses in the cavity.

Figure 18 shows the resultant TPV cell electrical power density and the STPV efficiency for scenarios 1 and 2, as a function of the concentration factor $(C)$ and the emitter aspect ratio $\left(L / R_{\mathrm{E}}\right)$. Note that scenario 1 provides an efficiency slightly above $5 \%$ and electrical power density slightly below $1 \mathrm{~W} / \mathrm{cm}^{2}$ for a concentration factor of $2000-3000$ suns and $L / R$ of about $3-4$ (Figure 18(a)). It matches with the previous predictions derived from the experimental data presented in this paper. Scenario 2 shows the efficiency that could be obtained improving the cavity optical confinement (Figure 18(b)). Note that efficiencies of $12-13 \%$ and electrical power densities close to $5 \mathrm{~W} / \mathrm{cm}^{2}$ could be obtained for the same combination of concentration and $L / R$. However, take into account that because this analysis assumes an ideal concentrator and that the cells are operated at room temperature, a more realistic achievable efficiency may be about $10 \%$.

\section{SUMMARY AND CONCLUSIONS}

In this paper, we have presented the development and characterization of a complete STPV system. Specifically, we have focused on the TPV cell array development, the characterization of the sunlight concentrator system, the measurement and estimation of the emitter temperature, 


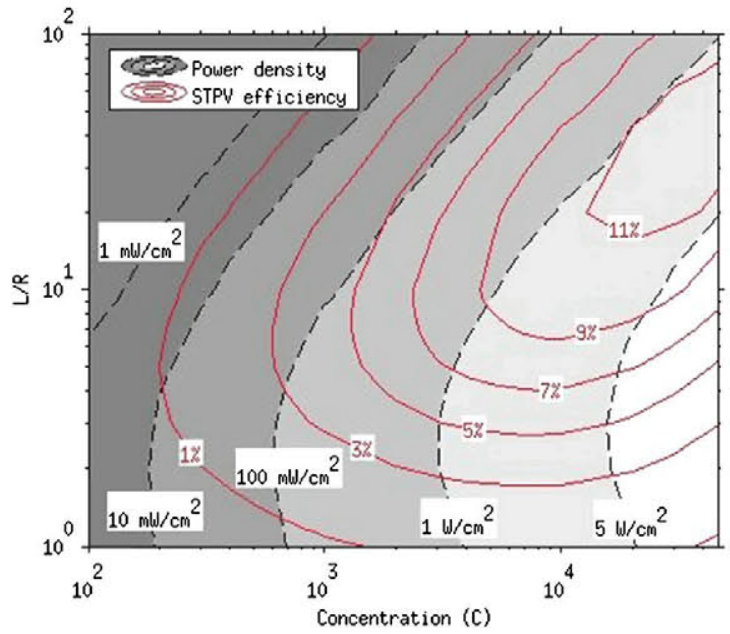

(a)

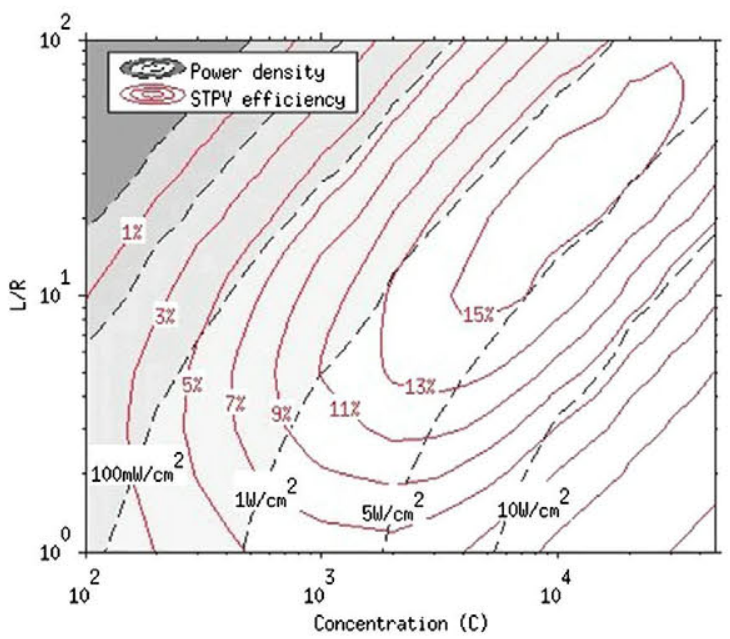

(b)

Figure 18. Contour plot of the TPV cells electrical power density $\left(\mathrm{FF} \cdot V_{\mathrm{oc}} \cdot \mathrm{JSC}\right)$ with superimposed iso-STPV efficiency $\left(\eta_{\mathrm{STPV}}\right)$ curves (solid lines) for scenarios 1 (a) and 2 (b), as a function of the concentration factor $(C)$ and the emitter aspect ratio $(L / R)$.

and the characterization of the full system under real outdoor irradiance conditions.

The TPV array comprises 24 germanium cells mounted on six TPV modules (four cells in each module), which form a hexagonal-shaped TPV generator that surrounds a cylindrical absorber/emitter. Within the module, the shingled arrangement has been used to obtain a high array packing density and to provide the series connection between the independent cells. Two different approaches have been presented to develop these modules. The TPV modules have been tested with a constant-voltage multiflash system, showing a relatively high FF (65-70\%) for relatively high current densities (up to $2 \mathrm{~A} / \mathrm{cm}^{2}$ ).
The sunlight concentrator system comprises a primary Fresnel lens $(60 \times 60 \mathrm{~cm})$ and a secondary meniscus lens. The concentrator efficiency has been measured for different geometrical concentration ratios using a broadband thermal detector. From these measurements, an optimum absorber inlet hole diameter of $12 \mathrm{~mm}$ has been identified (corresponding to a geometrical concentration factor of $3183 \times$ ). This diameter accounts for the maximum concentration efficiency $(67 \%)$ and the minimum absorber emission losses.

Several graphite cylindrical emitters (with different lengths and diameters) have been tested under concentrated sunlight. The temperature of these emitters has been measured by means of a thermocouple placed within the cylindrical absorber cavity. For high aspect ratio emitters (high $L / R$ ), the thermocouple temperature matches relatively well with the calculated temperatures obtained from the solution of an energy balance at the absorber/emitter component. However, for low aspect ratio emitters (low $L / R$ ), this setup has demonstrated providing overestimated temperature readings, surely because of the direct absorption of sunlight at the thermocouple. From these considerations, the estimated temperature for the graphite emitters are in the range of 800 $1200^{\circ} \mathrm{C}$, depending on the emitter dimensions, whereas for pure-tungsten and ARC-tungsten emitters is in the range of $1300-1500^{\circ} \mathrm{C}$.

Finally, the full STPV system has been mounted on a two-axis sun tracker to evaluate its performance under outdoor real conditions. This system has provided shortcircuit current densities of up to $0.95 \mathrm{~A} / \mathrm{cm}^{2}$, electric power densities of $62 \mathrm{~mW} / \mathrm{cm}^{2}$, and a conversion efficiency of $0.8 \%$. To our knowledge, this is the first overall solar-to-electricity efficiency reported for a complete STPV system. The very low efficiency is mainly due to the overheating of the cells (up to $120^{\circ} \mathrm{C}$ ) and to the concentrator optical losses, which prevent achievement of the optimum emitter temperature. It has been estimated that just by improving both aspects, efficiencies above 5\% would be achievable in the very short term and that efficiencies above $10 \%$ could be achieved with further improvements. This efficiency is still low compared with other PV technologies. However, the lower efficiency could be compensated by the great added value that represents the ability of generating power during dark periods, which is possible with these systems if thermal storage at the emitter/absorber component is incorporated. This ability would be of interest in most of the off-grid applications and also regarding grid management purposes.

\section{ACKNOWLEDGEMENTS}

This work has been developed within the frame of the European project FULLSPECTRUM SES6-CT-2003502620. We acknowledge all the partners of this project for their valuable support. Specifically, to the Photovoltaics Laboratory of Ioffe Physico-Technical Institute for manufacturing the tungsten emitters and the quartz 
chambers and for the very fruitful advices concerning the overall system design. To the Materials-Solar Cells and Technologies Department of Fraunhofer-ISE, for manufacturing the Ge cells. To the Materials Research and Applied Optics Department of Fraunhofer-ISE, for carrying out the anti-reflective coating of tungsten emitters. We want to acknowledge Dr. Giovanni Flamand, from the Solar Cell Technologies Group at IMEC, for carrying out the parallel gap welding of the cells. A. Datas acknowledges financial support from the 'Consejería de Educación de la Comunidad de Madrid y del Fondo Social Europeo (FSE)'.

\section{REFERENCES}

1. Swanson RM. A proposed thermophotovoltaic solar energy conversion system. In Proceedings of the IEEE, volume 67, 1979; 446-447.

2. Davies PA, Luque A. Solar thermophotovoltaics brief review and new look. Solar Energy Materials and Solar Cells 1994; 37(1): 11-22.

3. Chubb DL, Good BS, Lowe RA. Solar thermophotovoltaic (STPV) system with thermal energy storage. In 2nd NREL Conference on Thermophotovoltaic Generation of Electricity, number $\mathbf{3 5 8}$ 1995; 181-198.

4. Stone KW, Fatemi NS, Garverick LM. Operation and component testing of a solar thermophotovoltaic power system. In 25th IEEE Photovoltaic Specialists Conference. 1996; 1421-1424.

5. Datas A, Algora C. Analytical model of solar thermophotovoltaic systems with cylindrical symmetry: ray tracing approach. Progress in Photovoltaics 2009; 17: $526-541$.

6. Datas A, Algora C. Detailed balance analysis of solar thermophotovoltaic systems made up of single junction photovoltaic cells and broadband thermal emitters. Solar Energy Materials and Solar Cells 2010; 94(12): 2137-2147.

7. Bell RL Concentration ratio and efficiency in thermophotovoltaics. Solar Energy 1979; 23(3): 203-210.

8. Demichelis F, Minetti-Mezzetti E. A solar thermophotovoltaic converter. Solar Cells 1980; 1(4): 395-403.

9. Edenburn MW. Analytical evaluation of a solar thermophotovoltaic (TPV) converter. Solar Energy 1980; 24(4): 367-371.

10. Höfler H, Paul HJ, Ruppel W, Würfel P. Interference filters for thermophotovoltaic solar energy conversion. Solar Cells 1983; 10: 273-286.

11. Höfler H, Würfel P, Ruppel W. Selective emitters for thermophotovoltaic solar energy conversion. Solar Cells 1983; 10: 257-271.
12. Spirkl W, Ries H. Solar thermophotovoltaics: an assessment. Journal of Applied Physics 1985; 57(9): 4409-4414.

13. Würfel P, Ruppel W. Upper limit of thermophotovoltaic solar-energy conversion. IEEE Transactions on Electron Devices 1980; 27: 745-750.

14. Chaudhuri TK. A solar thermophotovoltaic converter using PBS photovoltaic cells. International Journal of Energy Research 1992; 16(16): 481-487.

15. Harder N-P, Würfel P. Theoretical limits of thermophotovoltaic solar energy conversion. Semiconductor Science and Technology 2003; 18: S151-S157.

16. Andreev VM, Khvostikov VP, Khvostikova OA, Rumyantsev VD, Gazarjan PY, Vlasov AS. Solar thermophotovoltaic converters: efficiency potentialities. In Sixth Conference on Thermophotovoltaic Generation of Electricity, Vol. 738, Luther J, Gopinath A, Coutts TJ (eds). AIP Conference Proceedings: Freiburg, Germany, 2004; 96-104.

17. Stone KW, Chubb DL, Wilt DM. Testing and modeling of a solar thermophotovoltaic power system. In 2nd NREL Conference on Thermophotovoltaic Generation of Electricity, number $\mathbf{3 5 8}$, 1995; 199-209.

18. Stone KW, Drubka RE, Kusek SM, Douglas M. A space solar thermophotovoltaic power system. In 31st Intersociety Energy Conversion Engineering Conference (IECEC 96). IEEE: Washington DC, USA, 1996; 1001-1006.

19. Stone KW, Kusek SM, Drubka RE. Analysis of solar thermophotovoltaic test data from experiments performed at McDonnell-Douglas. In 1st NREL Conference on Thermophotovoltaic Generation of Electricity, 1994; 153-162.

20. Stone KW, Leingang EF, Drubka RE. System performance of a solar thermophotovoltaic system for space and terrestrial application. In 30th Intersociety Energy Conversion Engineering Conference-Energy Technologies for a Sustainable Future (IECEC 95). IEEE: Washington DC, USA, 1995; A713-A718.

21. Stone KW, Leingang EF, Drubka RE. Test results from a solar thermophotovoltaic power experiment. In Proceedings of the American Solar Energy Society Annual Conference. Boulder, CO: San Jose, CA, USA, 1994; 174-178.

22. Stone KW, Leingang EF, Drubka RE. Solar thermophotovoltaic power experiments at McDonnellDouglas. In 29th Intersociety Energy Conversion Engineering Conference. IEEE: Washington DC, USA, 1994; 1692-1696.

23. Stone KW, Leingang EF, Kusek SM. On-sun test results of McDonnell Douglas' prototype solar thermophotovoltaic power system. In 1994 IEEE 1st 
World Conference on Photovoltaic Energy Conversion -24th IEEE Photovoltaic Specialists Conference1994, 1994. IEEE: Waikoloa, Hawaii, 2010-2013.

24. Stone K, McLellan S. Utility market and requirements for a solar thermophotovoltaic system. In 2nd NREL Conference on Thermophotovoltaic Generation of Electricity, number 358, 1995; 238-250.

25. Fatemi NS. A solar thermophotovoltaic electrical generator for remote power applications. Technical report, Essential Research, Inc., 1996.

26. Fatemi NS. A solar thermophotovoltaic electric generator for remote power applications. Technical report, Essential Research, Inc., 1998.

27. Garverick LM, Fatemi NS, Jenkins PP. Thermophotovoltaic technology development at Essential Research, Inc. In Space Technology and Applications International Forum (STAIF-98)-Progress in Expanding the Space Frontier, number 420, 1998; 1417-1422.

28. Horne E. Hybrid thermophotovoltaic power systems. Technical report, EDTEK, Inc., 2002.

29. Luque A, Martí A. FULLSPECTRUM: a new PV wave of more efficient use of the solar spectrum. Semiconductors 2004; 38(8): 936-940.

30. Datas A, Algora C, Zamorano JC, Corregidor V, Martín D, Bett AW, Dimroth F, Fernández J, Baudrit M, Hernández B. A solar TPV system based on germanium cells. In 7th World Conference on Thermophotovoltaic Generation of Electricity, volume 890 , Corregidor V Algora C, (ed), AIP Conference Proceedings: Madrid, Spain, 2006; 280-290.

31. Andreev VM, Grilikhes VA, Khvostikov VP, Khvostikova OA, Rumyantsev VD, Sadchikov NA, Shvarts MZ. Concentrator PV modules and solar cells for TPV systems. Solar Enegy Materials and Solar Cells 2004; 84: 3-17.

32. Andreev VM, Vlasov AS, Khvostikov VP, Khvostikova OA, Gazaryan PY, Sadchikov NA, Rumyantsev VD. Solar thermophotovoltaic converter with Fresnel lens and GaSb cells. In Conference Record of the 2006 IEEE 4th World Conference on Photovoltaic Energy Conversion. IEEE: Waikoloa, Hawaii, 2006; 644-647.

33. Andreev VM, Vlasov AS, Khvostikov VP, Khvostikova OA, Gazaryan PY, Sorokina SV, Sadchikov NA. Solar thermophotovoltaic converters based on tungsten emitters. Journal of Solar Energy Engineering 2007; 129: 298-303.

34. Andreev VM, Khvostikov VP, Vlasov AS, Gazaryan PY, Sadchikov A, Rumyantsev VD. Solar thermophotovoltaic system with high temperature tungsten emitter. In Photovoltaic Specialists Conference, 2005. Conference Record of the Thirty-first IEEE, 2005; 671-674.

35. Grilikhes VA, Ender AY, Kolyshkin N, Kuznetsov VI, Shvarts MZ. A high-temperature solar source of heat for a thermophotovoltaic generator: theory and experiment. Thermal Engineering 2007; 8: 620 625.

36. Khvostikov VP, Gazaryan PY, Khvostikova OA, Potapovich NS, Sorokina SV, Malevskaya AV, Shvarts MZ, Shmidt NM, Andreev VM. GaSb applications for solar thermophotovoltaic conversion. In 7th World Conference on Thermophotovoltaic Generation of Electricity. AIP: El Escorial, Madrid, Spain, volume 890, 2006; 139-148.

37. Khvostikov VP, Khvostikova OA, Gazaryan PY, Sorokina SV, Potapovich NS, Malevskaya AV, Shvarts MZ, Kaluzhniy NA, Andreev VM, Rumyantsev VD. Photoconverters for solar TPV systems. In 4th World Conference on Photovoltaic Energy Conversion. IEEE: Waikoloa, Hawaii, 2006; 667-670.

38. Rumyantsev VD, Khvostikov VP, Khvostikova OA, Gazaryan PY, Sadchikov NA, Vlasov AS, Ionova EA, Andreev VM. Structural features of a solar TPV systems. In 6th Conference on Thermophotovoltaic Generation of Electricity, volume 738, Luther J Gopinath A, Coutts TJ, (eds), AIP Conference Proceedings: Freiburg, Germany, 2004; 79-87.

39. Vlasov AS, Khvostikov VP, Khvostikova OA, Gazaryan PY, Sorokina SV, Andreev VM. TPV systems with solar powered tungsten emitters. In 7th World Conference on Thermophotovoltaic Generation of Electricity, volume 890, Corregidor V Algora C, (eds), AIP Conference Proceedings: Madrid, Spain, 2006; 327-334.

40. van der Heide J, Posthuma NE, Flamand G, Geens W, Poortmans J. Cost-efficient thermophotovoltaic cells based on germanium substrates. Solar Energy Materials and Solar Cells 2009; 93: 1810-1816.

41. Fernández J. Optimization of crystalline germanium for thermophotovoltaic and high-efficiency solar cells. $\mathrm{PhD}$ thesis, University Konstanz, 2010.

42. Fernández J, Dimroth F, Oliva E, Bett AW. Development of germanium TPV cell technology. In 22nd European Photovoltaic Solar Energy Conference and Exhibition 2007, European Commission, (ed). Milano: Italy, 2007; 516-519.

43. Fraas LM, Daniels WE, Avery JE, Samaras JE, Keyes JB. Shingle circuits for thermophotovoltaic systems, 2001.

44. Schlegl T, Dimroth F, Olm A, Bett AW. TPV modules based on $\mathrm{GaSb}$ structures. In 6th Conference on Thermophotovoltaic Generation of Electricity, volume 738, 2004; 285-293.

45. Keogh WM, Blakers AW, Cuevas A. Constant voltage $I-V$ curve flash tester for solar cells. Solar Energy Materials and Solar Cells 2004; 81: 183-196.

46. Datas A. Development of solar thermophotovoltaic systems. PhD thesis, Universidad Politecnica de Madrid, 2011. 